\title{
MEMÓRIA, TRAUMA E ESCRITA EM DIÁRIO DA QUEDA, DE MICHEL
}

\section{LAUB}

\begin{abstract}
Alex Keine de Almeida Sebastião ${ }^{1}$
Resumo: Trata-se de apresentar uma leitura da obra Diário da Queda, de Michel Laub, a partir da perspectiva da transmissão da memória e de sua relação com o trauma e a escrita. A título de introdução, faz-se um breve comentário acerca da estruturação da obra e também de sua eventual classificação no gênero autobiográfico. A seguir, recolhemos fragmentos da obra que nos permitem refletir sobre algumas questões como, por exemplo, estas: como se transmite a memória entre gerações? que destino dar ao excesso de memória, à imposição de lembrar? pode-se culpar um sobrevivente da Shoah pela ausência de testemunho, pelo seu silêncio? é possível romper a transmissão do trauma?
\end{abstract}

Palavras-chave: memória; trauma; escrita; Auschwitz.

Abstract: This paper presents a reading of Diary of The Fall, by Michel Laub, from the perspective of memory transmission and its relation to trauma and writing. As introduction, there's a brief comment on the book's structure and also on its eventual classification under the autobiographical genre. Then we gather fragments of the book which allow a reflection about some questions such as these: how is memory transmitted? what to do with excessive memory, with the imposition of remembering? may one blame a Shoah survivor for the absence of testimony, for his silence? is it possible to break the transmission of trauma?

Keywords: memory; trauma; writing; Auschwitz.

\footnotetext{
${ }^{1}$ Doutorando no Programa de Pós-Graduação em Estudos Literários, na Faculdade de Letras da Universidade Federal de Minas Gerais. E-mail: keine74@uol.com.br.
} 


\section{Introdução}

Diário da Queda, de Michel Laub, é um livro que marca o leitor. Parece haver ali uma verdade que consegue se fazer transmitir. Uma verdade que tem a ver com o trauma e também com a experiência de ser filho, de ser neto e de ser pai. Há uma dedicatória ao pai. A questão da memória está presente ao longo de todo o livro. É recorrendo à memória que o narrador nos conta sua história, na qual tanto seu pai quanto seu avô tem papel fundamental. Cabe observar que a obra já foi traduzida para outros idiomas e teve bom acolhimento da crítica tanto nacional quanto estrangeira. No Brasil, figurou em várias listas dos melhores livros publicados em 2011.

O livro é estruturado a partir de fragmentos numerados em sequência e reunidos em blocos com os seguintes títulos: Algumas coisas que sei sobre o meu avô; Algumas coisas que sei sobre o meu pai; Algumas coisas que sei sobre mim; Notas (1); Mais algumas coisas que sei sobre o meu avô; Mais algumas coisas que sei sobre o meu pai; Mais algumas coisas que sei sobre mim; Notas (2); Notas (3); A queda; O diário. Não há sumário e é discutível se os blocos citados consistem em capítulos. Em resenha de Guilherme Blender, colhemos a seguinte manifestação de Michel Laub: "Consegui dizer o maior número de coisas. Ter escrito em fragmentos possibilitou uma escrita mais solta que a os anteriores. Considero o meu melhor livro" (BLENDER, 2011).

Sobre os títulos e a estruturação dos blocos, nota-se que eles mimetizam algo do funcionamento da memória. Não se lê ali "todas as coisas que sei sobre o meu avô", mas sim "algumas coisas que sei sobre o meu avô". Não há pretensão de totalidade ou de esgotamento, assumindo-se uma escrita lacunar tal qual a memória. Do avô, passa-se ao pai, em seguida, ao próprio narrador, espaço para notas, e então, retorna-se ao avô com "mais algumas coisas que sei sobre o meu avô". Tampouco há uma separação rigorosa das memórias como poderíamos ser levados a crer pelos títulos dados aos blocos, que ora evocam o avô, ora o pai, ora o próprio narrador. Ainda que seja impossível alcançar uma separação absoluta das memórias relacionadas ao avô, ao pai e ao narrador, visto que no texto, todas elas nos são apresentadas a partir da memória do narrador, não é difícil imaginar uma apresentação mais cronológica, em que o foco narrativo iniciasse no avô, passasse ao pai, para 
depois chegar ao filho. Todavia, a opção do autor foi outra, evidenciando que, na memória, o tempo cronológico pode estar em segundo plano e que as lembranças criam seus próprios critérios de associação.

Podemos sempre buscar retomar a memória para visitar lembranças já conhecidas ou para recuperar outras que estavam meio perdidas. A memória vem, ela se esvai e ela retorna. Há uma repetição em que o mesmo e o diferente se mesclam em combinações infinitas. Sob certo aspecto, a lembrança rememorada traz o mesmo do vivido, sob outro, ela traz sempre um detalhe novo e único que concerne ao momento da rememoração.

A narrativa se passa em primeira pessoa, havendo identidade entre 0 narrador e o personagem principal. Ainda que o narrador não seja nomeado, a obra pode sugerir traços autobiográficos, visto que Michel Laub também tem origem judaica, nasceu em Porto Alegre, mudou-se para São Paulo, cursou direito e jornalismo e, quando o livro foi escrito, sua idade era próxima à do narrador. A dedicatória ao pai que abre o livro já suscita essa questão do gênero literário, visto que o leitor pode se perguntar: pai de quem: do autor ou do narrador?

Segundo Phillipe Lejeune, a autobiografia tem a seguinte definição: "narrativa retrospectiva em prosa que uma pessoa real faz de sua própria existência, quando focaliza sua história individual, em particular a história de sua personalidade" (2008, p. 16). Dentre os elementos listados por Lejeune como integrantes dessa definição, no caso de Diário da Queda, a dúvida fica sobre a identidade entre autor e narrador, visto que esse não é nomeado. Ainda segundo Lejeune, em caso de dúvida, trata-se de romance autobiográfico, categoria que reúne "todos os textos de ficção em que o leitor pode ter razões de suspeitar, a partir das semelhanças que acredita ver, que haja identidade entre autor e personagem, mas que o autor escolheu negar essa identidade ou, pelo menos, não afirmá-la" (2008, p. 29).

Em entrevista à Deutsche Welle, Michel Laub afirmou:

Tudo é autobiográfico num livro, porque o escritor se baseia na própria memória, nem que seja para inventar. Mas por exemplo, o personagem tem um pai que morreu de Alzheimer, e meu pai não morreu de Alzheimer. Mas claro que as sensações, as emoções que tem ali no meio vão, em algum 
momento, falar de coisas que senti algum dia. Você faz uma espécie de transplante do que sentiu. A perda do cachorro da infância é usada para falar de uma perda amorosa, por exemplo. (LAUB, 2013b; grifos meus)

A fala de Laub apresenta uma noção menos corrente e bem mais ampla de autobiografia, visto que não se prende à distinção entre realidade e ficção, ainda que tenha na memória o seu lastro fundamental. Vale dizer, memória não equivale a um passado real em oposição à ficção. Para Laub, a memória é o celeiro onde o escritor pode buscar não só fatos que ele efetivamente vivenciou, como também as sensações e emoções que lhe servirão de matériaprima para a invenção de fatos outros que transcendem a realidade.

Se, por um lado, Laub afirma que seu livro é autobiográfico como todo livro o é, visto que se vale de algum modo da memória do próprio escritor, por outro, ele nega a presença do caráter autobiográfico, entendido como representação da realidade em que estaria ausente a ficção. Em suas palavras: "Muitas pessoas acham que é autobiográfico por ser escrito em primeira pessoa, mas não é." (LAUB, 2013a). Em outra entrevista, ele ponderou: "o livro não é tão autobiográfico como os leitores pensam: é só $40 \%$ autobiográfico" (LAUB, 2013b).

\section{Memória}

A temática da memória atravessa todo o livro Diário da queda, constituindo a teia em que o texto se sustenta. Ao nos apresentar suas memórias, o narrador, neto de um sobrevivente de Auschwitz, é levado a abordar também as memórias do avô e as memórias do pai. A relação entre essas memórias é fundamental na obra, bem como suas respectivas relações a Auschwitz, quer dizer, ao fato de que o avô passou por esta vivência: ser um judeu prisioneiro do regime nazista, no campo de extermínio de Auschwitz. Como se transmite a memória de uma geração à outra? Como a memória coletiva é apropriada pela memória individual? Como se transmite a memória de um pai a um filho e em que circunstâncias?

A memória pode ser uma prisão, é o que podemos concluir do primeiro parágrafo do livro: 
Meu avô não gostava de falar do passado. O que não é de estranhar, ao menos em relação ao que interessa: o fato de ele ser judeu, de ter chegado ao Brasil num daqueles navios apinhados, o gado para quem a história parece ter acabado aos vinte anos, ou trinta, ou quarenta, não importa, e resta apenas um tipo de lembrança que vem e volta e pode ser uma prisão ainda pior que aquela onde você esteve. (LAUB, 2011, p. 8)

Que lugar conceder à memória? Poderíamos dizer que o mal de arquivo ocorre não só em caso de lacuna da memória, mas também de excesso da memória? Que destino dar ao excesso de memória, à imposição de lembrar? A certa altura do relato, o narrador desabafa: "por mais que tanta gente tivesse morrido em campos de concentração não fazia sentido que eu precisasse lembrar disso todos os dias" (LAUB, 2011, p. 37). Se ao longo da infância, o narrador sonhava com as perseguições aos judeus, com "as suásticas ou as tochas dos cossacos do lado de fora da janela" (LAUB, 2011, p. 36), aos poucos isso vai mudando. Ao questionar sua relação com essa memória massacrante, ele consegue se descolar um pouco dela e elaborar seu jeito particular de lidar com isso que lhe foi transmitido.

Em Diário da Queda, o termo Auschwitz é utilizado para se referir não só ao campo de concentração de Auschwitz propriamente dito, mas também, de modo mais amplo, à Shoah ${ }^{2}$. Sobre a repetição do tema já abordado em profusão, o narrador se justifica ao apontar para a sua relação subjetiva com Auschwitz: "[...] então nem por um segundo me ocorreria repetir essas ideias se elas não fossem, em algum ponto, essenciais para que eu possa também falar do meu avô, e por consequência do meu pai, e por consequência de mim" (LAUB, 2011, p. 9).

O avô escreve seus cadernos de memórias em seus últimos anos de vida, tal como o pai que, somente com a aproximação da morte, envia ao filho-

\footnotetext{
${ }^{2}$ Em O que resta de Auschwitz, Giorgio Agamben reconstrói o percurso etimológico do termo holocausto e faz sua crítica: "No caso do termo 'holocausto', estabelecer uma vinculação, mesmo distante, entre Auschwitz e o olah bíblico, e entre a morte nas câmaras de gás e a 'entrega total a causas sagradas e superiores' não pode deixar de soar como uma zombaria" (1998, p. 40). O termo Shoah, utilizado pelos judeus, e que significa 'devastação, catástrofe' seria um eufemismo, na concepção de Agamben. Ele se vale do termo Auschwitz para se referir a esse mesmo evento histórico também nomeado de "Holocausto" e "Shoah". O narrador de Diário da Queda adota o mesmo termo, ressalvada uma ou outra ocorrência de "Holocausto".
} 
narrador um primeiro arquivo com suas memórias. Ao comparar os dois feixes de memórias, o narrador engancha aí um terceiro feixe de memórias, o seu.

As memórias do meu avô podem ser resumidas na frase como o mundo deveria ser, e daria até para dizer que as do meu pai são algo do tipo como as coisas foram de fato, e se ambos são como que textos complementares que partem do mesmo tema, a inviabilidade da experiência humana em todos os tempos e lugares, o meu avô imobilizado por isso, o meu pai conseguindo ir adiante apesar disso, e se é impossível falar sobre os dois sem ter de também firmar uma posição a respeito, o fato é que desde o início escrevo este texto como justificativa para essa posição. (LAUB, 2011, p. 146).

O ato do avô de escrever seus cadernos de memórias constitui um fato decisivo para o narrador, visto que é a partir dele que Auschwitz deixa de ser somente um marco histórico e coletivo, para ser também e, sobretudo, um marco de sua história pessoal. Os rastros da memória que são transmitidos ao longo da linhagem familiar ocasionam a apropriação da memória coletiva pelo narrador de um modo muito particular e dramático.

Michel Pollak aponta que "quando se trata da memória herdada, podemos também dizer que há uma ligação fenomenológica muito estreita entre a memória e o sentimento de identidade" (1992, p. 204). A memória familiar é fonte potencial de conflitos e de intensa disputa, visto que ela contribui para sustentar ou para desestabilizar a identidade de cada um dos membros da família. A imagem de si que uma pessoa constrói ao longo da vida e apresenta para si mesma e para os outros está ligada, em graus variáveis, não só à memória de sua própria história subjetiva, mas também à memória que Ihe foi transmitida da história de seus ascendentes. O livro de Laub nos mostra que o conflito pode girar em torno não do conteúdo dessa memória herdada, mas sim da postura a ser tomada frente a ela. Ali, o narrador se revolta tanto contra o silêncio impotente do avô quanto contra a eloquência sufocante do pai sobre Auschwitz.

\section{Trauma}

Nossa concepção atual de trauma, em sua modalidade psíquica, é grandemente tributária da construção de Freud sobre o tema, acrescida da 
contribuição de Lacan. Freud nos propõe pensar o evento traumático como "uma grande ruptura que foi causada no escudo protetor contra os estímulos" (1920, p. 42). O aparelho psíquico é submetido a uma excitação muito além de sua capacidade de processamento, gerando desestabilização e a suspensão da homeostase presidida pelo princípio de prazer. Após sua ocorrência, o fato traumático passa a sugar toda a energia disponível no aparelho psíquico e instala-se a compulsão à repetição. A memória parece fixar-se em um passado que não passa. Os sonhos com o momento do trauma são frequentes, como costumam relatar os soldados que voltam de uma guerra. Freud reconhece aqui uma exceção à regra de que os sonhos constituem a realização de desejos. Os sonhos associados a um evento traumático são um esforço da psique para "dominar retrospectivamente o estímulo" (Ibid.) e apontam para algo que se situa além (ou aquém) do princípio do prazer.

Já Lacan, ao propor o retorno a Freud, traz-nos algumas inovações, como, por exemplo, a noção de real. O real não se confunde com a realidade e tem uma relação de exterioridade com a linguagem. Ele constitui, ao lado do imaginário e do simbólico, um dos registros que compõem a experiência humana. Para Lacan, o trauma tem a ver com um encontro com o real. Um encontro para o qual nunca se está preparado e sobre o qual é difícil dizer.

$\mathrm{Na}$ trilha de Dominick La Capra, costuma-se distinguir entre trauma histórico e trauma estrutural (conf. LA CAPRA apud SULEIMAN, 2006, pp. 132133). Esse último consistiria no trauma fundador da subjetividade, inerente à condição humana, decorrendo do fato do nascimento, da entrada na linguagem e da exposição ao sexual. Já o trauma histórico, tem um caráter contingente, visto que nem todas as pessoas vivenciam algo do gênero. Ele pode ser tanto de aspecto coletivo, como ser prisioneiro num campo de concentração nazista, quanto de aspecto individual, como ser uma criança abusada sexualmente.

O trauma histórico origina um marco na vida de um sujeito, instituindo um antes e um depois do fato traumático. É o que podemos perceber quando o narrador de Diário da Queda afirma: "Se eu tivesse que falar de algo meu, começaria com a história do colega que caiu na festa" (LAUB, 2011, p. 15), e também: "Para mim tudo começa aos treze anos, quando deixei João cair na festa de aniversário" (LAUB, 2011, p. 33). Na festa de 13 anos de seu colega 
João, o aniversariante é jogado para cima 13 vezes, como é usual na celebração do Bar Mitzvah, um rito de passagem judaico. Acontece que "nesse dia a rede abriu na décima terceira queda e o aniversariante caiu de costas no chão" (LAUB, 2011, p. 10). Os colegas que jogavam João para cima e o amparavam em seguida, dentre os quais, estava o narrador, combinaram de se afastar na décima terceira vez, para que João caísse no chão.

O aniversariante era bolsista, filho de um cobrador de ônibus e não era judeu. Por não ser judeu, João era chamado gói e sofria forte assédio por parte dos outros alunos, majoritariamente judeus. Ele costumava ser enterrado na areia, enquanto os colegas cantavam uma música dizendo "come areia, come areia, come areia, gói filho de uma puta" (LAUB, 2011, p. 22). Em virtude da queda no seu aniversário, João lesionou uma vértebra, ficou acamado, usou colete ortopédico e foi submetido a sessões de fisioterapia. A partir daí, não é só a vida de João que muda, mas também e, principalmente, a vida do narrador. Se João sofre uma lesão corporal, o narrador experimenta um choque psíquico que retornará em sonhos: "eu sonhei muitas vezes com o momento da queda, um silêncio que durou um segundo, talvez dois" (LAUB, 2011, p. 12). É também logo após esse fato traumático que o narrador localiza o início do uso abusivo de álcool: "eu comecei a beber aos catorze anos, depois que mudei de escola junto com João" (LAUB, 2011, p. 63). Mais à frente, ele engancha também aí sua herança traumática: "Aos catorze anos eu sentei na cama com a garrafa de uísque que tinha pego (sic) no armário porque sabia que o meu avô nunca deixou de pensar em Auschwitz" (LAUB, 2011, p. 99).

Ao longo do livro, o narrador confronta o trauma do avô, a passagem por Auschwitz, com o seu trauma pessoal, a queda de João. O narrador sequer chegou a conhecer seu avô pessoalmente, visto que ele morreu quando o pai do narrador tinha apenas catorze anos. A dimensão gigantesca de Auschwitz com seus milhões de vítimas contrapõe-se à queda de João com sua única vítima aparente. Sob outra perspectiva, a distância de Auschwitz contrasta com a proximidade de João. Vejam-se, por exemplo, os seguintes fragmentos:

Se na época perguntassem o que me afetava mais, ver o colega daquele jeito ou o fato de meu avô ter passado por Auschwitz, e por afetar quero dizer sentir intensamente, como algo palpável e presente, uma lembrança que não precisa ser 
evocada para aparecer, eu não hesitaria em dar a resposta. (LAUB, 2011, p. 13)

[...] comecei a ter vergonha de ter gritado gói filho de uma puta, e isso se misturava com o desconforto cada vez maior diante do meu pai, uma rejeição à performance dele ao falar de antissemitismo, porque eu não tinha nada em comum com aquelas pessoas além do fato de ter nascido judeu, e nada sabia daquelas pessoas além do fato de elas serem judias, e por mais que tanta gente tivesse morrido em campos de concentração não fazia sentido que eu precisasse lembrar disso todos os dias. (LAUB, 2011, p. 37)

[...] mesmo que Auschwitz seja considerada a maior tragédia do século $X X$, o que inclui milhões de pessoas que morreram em guerras e massacres e regimes de toda a espécie, uma exposição burocrática de estatísticas sobre vítimas que desapareceram há tanto tempo e que, mesmo o meu avô, e até o meu pai considerando o que ele acabou sofrendo indiretamente em virtude disso, jamais teriam uma fração da importância que João tinha para mim aos catorze anos? (LAUB, 2011, p. 121)

Há um questionamento frequente do narrador em relação à obrigação de relembrar Auschwitz demandada por seu pai. O desconforto diante do pai com seu discurso sobre antissemitismo se mistura com a vergonha da participação na queda de João. Do confronto entre João e Auschwitz, o texto desliza para uma relação de causa e efeito: "Não fazia sentido que eu quase tivesse deixado um colega inválido por causa disso, ou porque de alguma forma havia sido influenciado por isso, o discurso do meu pai como uma reza antes das refeições, a solidariedade aos judeus do mundo" (LAUB, 2011, p. 37).

Na briga mais séria que teve com o pai, o narrador diz que não está nem aí para o judaísmo e nem para o que tinha ocorrido com o avô, e acrescenta "devagar, olhando nos olhos dele, que eu queria que ele enfiasse Auschwitz e o nazismo e o meu avô bem no meio do cu" (LAUB, 2011, p. 50). Em meio às lembranças da relação conturbada com o pai, o narrador chega mesmo a responsabilizá-lo pela queda de João:

[...] porque de algum modo meu pai era responsável pelo que aconteceu com João, aquelas histórias todas sobre 0 Holocausto e o renascimento judeu e a obrigação de cada judeu no mundo de se defender usando qualquer meio, o inimigo que você nunca deixará de enfrentar, em quem você nunca mais deixará de pensar porque agora ele está numa cadeira de rodas. (LAUB, 2011, p. 70) 
A reação do avô após o trauma passa pelo silêncio e, nos últimos anos de vida, pela escrita compulsiva de cadernos e mais cadernos onde as marcas do sujeito parecem ter-se esvaído. Uma escrita que perpetua o silêncio. Como observa o narrador: "Do ramo da família do meu avô morreram todos em Auschwitz, e não há uma linha a respeito deles nos cadernos. Não há uma linha sobre o campo em si, quanto tempo meu avô ficou lá, como fez para sobreviver, o que sentiu quando foi libertado" (LAUB, 2011, p. 30).

O silêncio pós-traumático pode se apresentar sob modos diversos, variando conforme a sua motivação. A partir de Pollak, podemos apontar o silêncio conciliatório, em que os sobreviventes que retornam aos seus lares precisam conviver com aqueles que presenciaram sua deportação, o silêncio culpado, em que as vítimas trazem um sentimento de culpa pelo ocorrido, e o silêncio benevolente, em que há uma preocupação com "poupar os filhos de crescer na lembrança das feridas dos pais" (POLLAK, 1989, p. 6). Podemos acrescentar a essa tipologia o silêncio traumático propriamente dito, não intencional, em que o sujeito fracassa em trazer para a linguagem algo da experiência vivenciada.

Os sobreviventes da "Shoah" relatam que a experiência traumática a que foram submetidos gera tanto a necessidade premente de testemunhar quanto a sensação da impossibilidade de fazê-lo. Alguns não abandonam o silêncio, como é o caso do avô do narrador. Podemos perguntar se haveria uma obrigação moral para os sobreviventes de testemunhar. Podemos fazer recair sobre os ombros de um sobrevivente, além da carga do trauma, a culpa pela ausência de um testemunho?

\section{Escrita}

Desde a Antiguidade, debate-se a diferença entre escrita e fala no seio da linguagem. No Fedro de Platão, Sócrates aponta para os perigos da escrita, dentre os quais está o fato de ser perniciosa para a memória. O registro da fala através de inscrições em um suporte material dispensaria a memória de seu trabalho de retenção. Atualmente, consideramos a escrita muito mais uma aliada da memória do que sua oponente. Isso não exclui o fato de que fala e escrita continuam a conservar suas especificidades. 
No âmbito da literatura de testemunho, em que medida um relato oral se distingue de um relato escrito? Falar ou escrever gera consequência sobre a fidelidade do testemunho, sobre sua carga de verdade? A imaginação daquele que presta seu testemunho estaria mais favorecida quando ele fala ou quando ele escreve? Sob a perspectiva da recepção, o impacto de um testemunho é variável conforme ele seja escutado ou lido? Essas são apenas algumas das questões que podem ser suscitadas pela consideração de fala e escrita como registros diversos no campo testemunhal.

Em Diário da Queda, a escrita ocupa o primeiro plano. O próprio livro é produto da escrita de um autor, Michel Laub. Enquanto o narrador escreve o relato de suas memórias, ficamos sabendo que seu avô escreveu em cadernos e que seu pai começou a lhe enviar suas memórias escritas em um primeiro arquivo de vinte ou trinta páginas. Têm-se três gerações de homens da mesma família que, cada um a seu modo, encontram na escrita uma via de elaboração e transmissão da memória.

O avô escreve: "Sesefredo - pensão no centro de Porto Alegra que é um estabelecimento amplo e asseado, quieto nas manhãs e aconchegante no início da noite, localizado num prédio que é sólido tanto que sobreviveu a um incêndio e possui bons ângulos em relação ao sol' (LAUB, 2011, p. 78). Os dezesseis cadernos do avô são escritos de maneira fragmentária, sob a forma de verbetes de dicionário em que se destaca a impessoalidade do tom para descrever um mundo insuportavelmente perfeito. Como julgar alguém que passou pela experiência de ser prisioneiro em Auschwitz, o superstes, o sobrevivente, pelo que escreveu ou deixou de escrever? O narrador, após comparar o avô a Primo Levi, propõe: "enxergar meu avô não como vítima, mas como homem e marido e pai, que deve ser julgado como qualquer outro homem e marido e pai” (LAUB, 2011, p. 81).

O pai escreve: "Minha mãe nunca soube que eu às vezes me trancava no quarto para chorar. Ninguém na loja soube que eu fechava a porta do banheiro, no meio da manhã, e ficava lá dez minutos, meia hora chorando",

\footnotetext{
${ }^{3} \mathrm{O}$ choro insistente deve-se ao fato de o pai do narrador ter encontrado seu próprio pai morto sobre a escrivaninha do escritório de casa, logo após haver cometido suicídio com uma arma de fogo. (cf. LAUB, 2011, p. 104)
} 
(LAUB, 2011, p. 141). E ainda: "Eu chorava de raiva e vergonha, mas eu não queria mais perder meu tempo falando a respeito. Eu já falei muito. Ou não falei, mas acho que você entendeu. Eu queria encerrar esse assunto porque é uma história que não interessa tanto a você" (LAUB, 2011, p. 145). Trata-se de uma outra escrita em que o sujeito, além de se revelar no texto, interpela aquele a quem a narrativa se endereça: seu filho. O trauma de Auschwitz se transmite pelo silêncio, pelo suicídio, pelos cadernos de cujo texto o autor está em estado de desaparecimento ${ }^{4}$. As duas escritas, do avô e do pai, são comparadas pelo narrador em alguns momentos, como neste:

Não há como ler as memórias do meu pai sem ver nelas o reflexo dos cadernos do meu avô. Não só porque ambos resolveram passar seus últimos anos entregues ao mesmo tipo de projeto, e seria ridículo argumentar que isso aconteceu por acaso, mas porque em pontos muito específicos os registros dos dois são opostos. (LAUB, 2011, p. 132)

O narrador escreve: "Ter um filho é deixar para trás a inviabilidade da experiência humana em todos os tempos e lugares, como se perdesse 0 sentido falar sobre as maneiras como ela se manifesta na vida de qualquer um, e as maneiras como cada um tenta e consegue se livrar dela" (LAUB, 2011, p. 150). Sob o espectro das escritas do avô e do pai, o narrador procura encontrar seu próprio tom, reagindo à "inviabilidade da experiência humana em todos os tempos e lugares". Sua reação vem através da própria escrita e culmina na realização da possibilidade de ter um filho, dando sequência à corrente de gerações.

Ao longo do livro, podemos perceber o relato do narrador como um acerto de contas tanto com seu avô quanto com seu pai. Há um tom de censura ao avô pelo silêncio sobre Auschwitz e ao pai pela eloquência acerca do mesmo tema. Na página final do livro, o narrador se dirige ao filho por vir com a promessa de fazer diferente: "Porque não vou atrapalhar sua infância insistindo no assunto. Não vou estragar sua vida fazendo com que tudo gire em torno disso. Você começará do zero sem necessidade de carregar o peso disso e nada além do que descobrirá sozinho" (LAUB, 2011, p. 151).

\footnotetext{
${ }^{4}$ Nos estudos sobre a literatura de testemunho, encontram-se as expressões "trauma secundário" e "testemunho secundário", referindo-se à segunda ou à terceira geração das vítimas.
} 
Como observa Márcio Seligmann-Silva, há que se lembrar de esquecer e há que não se esquecer de lembrar. Ele nos traz a seguinte citação de Nietzsche:

\begin{abstract}
A alegria, a boa consciência, o ato feliz, a confiança naquilo que vem - tudo isso depende em cada indivíduo assim como no povo, da existência de uma linha que separe o visível, claro, do que não pode ser clareado e escuro, de que se saiba tanto esquecer na hora certa, como também se recorde na hora certa, de que as pessoas sintam com um instinto forte quando é necessário sentir-se de modo histórico ou não-histórico. Essa é a proposição a que o leitor é justamente convidado a observar: o ahistórico assim como o histórico são igualmente necessários para a saúde de cada indivíduo, de um povo e de uma cultura. (NIETZSCHE apud SELIGMANN-SILVA, 2003, pp. 60-61)
\end{abstract}

A memória é resultado de lembrança e esquecimento, do trabalho de tecer e destecer um certo equilíbrio entre lembrar e esquecer parece ser uma boa diretriz para a memória. Mas Seligmann-Silva qualifica de inocente a ideia de que podemos controlar nossa memória (2003, p. 62). Em Diário da Queda, o desequilíbrio decorre de um excesso de lembrança de Auschwitz, levando o narrador a querer que seu filho "comece do zero". Será possível começar do zero no sentido de não receber nenhuma herança da memória daqueles que nos precederam? Podemos ler essa promessa do narrador como um desejo de escapar à repetição do trauma, de romper a transmissão de Auschwitz.

\title{
REFERÊNCIAS
}

AGAMBEN, Giorgio. O que resta de Auschwitz: o arquivo e a testemunha (Homo Sacer III). [1998] Trad. Selvino J. Assman. São Paulo: Boitempo, 2008. BLENDER, Guilherme. Michel Laub se rende ao judaísmo pela primeira vez. Folha de São Paulo, de 19 mar. 2011. Disponível em: http://www1.folha.uol.com.br/ilustrada/890674-michel-laub-se-rende-aojudaismo-pela-primeira-vez.shtml. Acesso em: 27 nov. 2015.

FREUD, Sigmund. Além do princípio do prazer [1920]. In: Edição

Standard Brasileira das Obras Psicológicas Completas de Sigmund Freud. Trad. Jayme Salomão. Rio de Janeiro: Imago, 1996. v.XVIII. pp. 11-75. 
LAUB, Michel. Diário da queda. São Paulo: Companhia das Letras, 2011. Algumas coisas que ficamos a saber sobre Michel Laub. Ciberescritas, 17 dez 2013.

Disponível

em:

http://blogues.publico.pt/ciberescritas/2013/12/17/algumas-coisas-que-ficamosa-saber-sobre-michel-laub/?utmsource=rss\&utmmedium=rss\& utmcampaign =algumas-coisas-que-ficamos-a-saber-sobre-michel-laub. Acesso em: 22 nov. 2015. Entrevista a Isabel Coutinho. [2013a]

. Tudo num livro é autobiográfico, diz Michel Laub. Folha de São Paulo: online, 17 out 2013.2 Disponível em: http://www1.folha.uol.com.br/dw/2013/10/1356838-tudo-num-livro-eautobiografico-diz-michel-laub.shtml. Acesso em: 21 nov. 2015. Entrevista concedida à Deutsche Welle. [2013b]

LEJEUNE, Philippe. O pacto autobiográfico: de Rousseau à Internet. [2008] Trad. Jovita Noronha e Maria Inês Guedes. 2. ed. Belo Horizonte: Ed. UFMG, 2014.

POLLAK, Michel. Memória, esquecimento, silêncio. Estudos Históricos, v.2, n.3, Rio de Janeiro, p. 3-15, 1989. Disponível em: http://bibliotecadigital.fgv.br/ojs/index.php/ reh/article/view/2278/1417. Acesso em: 21 nov. 2015.

. Memória e identidade social. Estudos Históricos, v. 5, n. 10, Rio de Janeiro, pp. 200-212, 1992. Disponível em: http://bibliotecadigital.fgv.br/ojs/index.php/reh/ article/view/1941/1080. Acesso em: 21 nov. 2015.

SELIGMANN-SILVA, Márcio. Reflexões sobre a memória, a história e o esquecimento. In: SELIGMANN-SILVA, Márcio (org.). História, memória, literatura: $O$ testemunho na era das catástrofes. Campinas: Ed. Unicamp, 2003, pp. 59-89.

SULEIMAN, Susan Rubin. Revision: Historical Trauma and Literary Testimony. In: . Crises of Memory and the Second World War. Cambridge, London: Harvard University Press, 2006, pp. 132-158. 